\title{
Nitroglycerin enhances the propagation of cortical spreading depression: comparative studies with sumatriptan and novel kynurenic acid analogues
}

This article was published in the following Dove Press journal:

Drug Design, Development and Therapy

20 December 2016

Number of times this article has been viewed

\author{
Levente Knapp' \\ Bence Szita' \\ Kitti Kocsis 1,2 \\ László Vécsei ${ }^{2,3}$ \\ József Toldi ${ }^{1,2}$
}

'Department of Physiology, Anatomy, and Neuroscience, University of Szeged, ${ }^{2}$ MTA-SZTE Neuroscience Research Group, ${ }^{3}$ Department of Neurology, Faculty of Medicine, Albert Szent-Györgyi Clinical Centre, University of Szeged, Szeged, Hungary

Correspondence: József Toldi Department of Physiology, Anatomy, and Neuroscience, University of Szeged, 52 Közép Fasor, Szeged 6726, Hungary

Tel +3662544149

Fax +36 62544291

Email toldi@bio.u-szeged.hu
Background: The complex pathophysiology of migraine is not yet clearly understood; therefore, experimental models are essential for the investigation of the processes related to migraine headache, which include cortical spreading depression (CSD) and NO donor-induced neurovascular changes. Data on the assessment of drug efficacy in these models are often limited, which prompted us to investigate a novel combined migraine model in which an effective pharmacon could be more easily identified.

Materials and methods: In vivo electrophysiological experiments were performed to investigate the effect of nitroglycerin (NTG) on CSD induced by $\mathrm{KCl}$ application. In addition, sumatriptan and newly synthesized neuroactive substances (analogues of the neuromodulator kynurenic acid [KYNA]) were also tested.

Results: The basic parameters of CSDs were unchanged following NTG administration; however, propagation failure was decreased compared to the controls. Sumatriptan decreased the number of CSDs, whereas propagation failure was as minimal as in the NTG group. On the other hand, both of the KYNA analogues restored the ratio of propagation to the control level.

Discussion: The ratio of propagation appeared to be the indicator of the effect of NTG. This is the first study providing direct evidence that NTG influences CSD; furthermore, we observed different effects of sumatriptan and KYNA analogues. Sumatriptan changed the generation of CSDs, whereas the analogues acted on the propagation of the waves. Our experimental design overlaps with a large spectrum of processes present in migraine pathophysiology, and it can be a useful experimental model for drug screening.

Keywords: migraine, cortical spreading depression, nitroglycerin, sumatriptan, kynurenic acid analogues

\section{Introduction}

Migraine is one of the most common neurological disorders, affecting $17 \%$ of women and $6 \%$ of men in the US. ${ }^{1}$ The environmental triggers eliciting migraine headache are diverse. The characteristic phases include aura (in a third of patients), headache, nausea, and hypersensitivity. In subgroups of patients, migraine headache is a wellmanaged condition; however, the therapeutic efficacy of available antimigraine drugs is in many cases limited, which necessitates unabated research efforts. The two main categories in migraine therapy include the acute and the preventive (ie, prophylactic) approaches. In acute therapy, different triptans (eg, sumatriptan) and nonsteroidal anti-inflammatory drugs are mainly used, whereas calcium-channel blockers, serotonin (ie, 5-hydroxytriptamine [5-HT]) antagonists, and $\beta$-blockers are among the drugs used for prophylaxis. Even though the research related to the processes involved in the 
pathomechanism of migraine has been a focus for decades, these have not yet been fully elucidated. Therefore, animal experiments are essential for further investigation of the pathophysiological processes related to migraine headache, and also for testing new substances aimed at mitigation of symptoms. The different mechanisms of migraine can be investigated from various aspects by a number of experimental models based on the sensitization or the stimulation of the trigeminal system, including the investigation of cortical spreading depression (CSD) and changes in the neurovascular system induced by NO donors. ${ }^{2}$

CSD is the electrophysiological correlate of migraine aura, and represents a potential trigger for headache. ${ }^{3}$ It is an intense self-propagating wave of depolarization involving neuronal and glial cells in the cerebral cortex, which is independent of functional areas and arterial territories. ${ }^{4} \mathrm{CSD}$ spreads at a velocity of 3-6 mm/min and causes massive changes in ionic homeostasis. Glutamatergic mechanisms have primary roles in the propagation of CSD. Indeed, CSD cannot be induced in cases of either P/Q-type calcium channels or $N$-methyl-Daspartate (NMDA) receptors being blocked in brain slices in vitro, ${ }^{5}$ or when antagonists of calcium channels or NMDA receptors are used in vivo. ${ }^{6,7}$ In addition, CSD upregulates several receptors in hippocampal and striatal territories, such as $\gamma$-aminobutyric acid $A$, different cholinergic $\left(\mathrm{M}_{1 / 2}, \alpha_{1 / 2}\right)$, 5-HT serotonergic, and $\mathrm{D}_{1}$ dopaminergic, as well as NMDA-, $\alpha$-amino-3-hydroxy-5-methyl-4-isoxazolepropionic acidand kainate-sensitive glutamatergic receptors. ${ }^{8,9}$ Therefore, in addition to glutamatergic mechanisms, alterations in other neurotransmitter systems participate in CSD as well. CSD also has an effect on cerebral blood flow, being associated with an initial increase in the blood flow via arteriolar dilation (mediated predominantly by NO), which subsequently turns into long-term oligemia. ${ }^{10,11}$

Experimental administration of NO donors, such as nitroglycerin (NTG), is a widely used method to model head pain. NTG elicits headache in both animals and humans. ${ }^{12,13}$ Systemic NTG administration evokes alterations in meningeal and cortical blood flow, ${ }^{14,15}$ increases the level of calcitonin gene-related peptide, and induces c-Fos expression in different brain areas associated with pain perception. ${ }^{16}$

With the use of these migraine models, several promising substances acting via various mechanisms can be investigated. The neuroactive metabolites of the kynurenine system provide a spectrum of possibilities to interfere with different neuropathological processes. ${ }^{17,18}$ Following the publication of the first studies suggesting the role of kynurenines in migraine, ${ }^{19}$ a subsequent series of research proved the beneficial effects of kynurenine-related pharmacologi- cal manipulations in migraine models. ${ }^{20,21}$ Among these substances, kynurenic acid (KYNA) has potential neuroprotective action by interfering with glutamatergic excitotoxicity. The peripheral administration of KYNA provides a number of promising results; however, these effects are limited, because of the low penetration of KYNA through the blood-brain barrier. ${ }^{22}$ Therefore, structurally modified KYNA derivates with better pharmacokinetic profiles may serve as useful tools against a large spectrum of neuropathological processes.

In this study, our aim was to investigate the effect of NTG on CSD, so as to create and validate a combined experimental migraine model, enabling the investigation of antimigraine drugs and the selection of other substances affecting the pathomechanism of migraine for further examinations. Also, we applied NTG with other molecules, including sumatriptan and novel analogues of KYNA, prior to the induction of CSD to test our combined experimental migraine model and investigate the effects of these molecules in this setting.

\section{Materials and methods}

Animals and surgery

All procedures used in this study were in accordance with the guidelines of the European Communities Council Directives (2010/63/EU) and the Hungarian Act for the Protection of Animals in Research (XXVIII.tv. 32. §). The study was approved by the National Scientific Ethical Committee on Animal Experimentation (National Competent Authority in Hungary), with the license number XX./842/2016. Male Wistar rats weighing 250-300 g were used. Animals were housed in polyethylene cages at room temperature $\left(22^{\circ} \mathrm{C}\right)$ with a 12-hour light-dark cycle (lights on at $6 \mathrm{am}$ ) and free access to water and rodent laboratory chow.

All procedures were carried out under deep urethane anesthesia ( $1.5 \pm 0.2 \mathrm{~g} / \mathrm{kg}$ body weight), as it provides very stable anesthesia in rats, lasting for several hours and being optimal for CSD recordings. ${ }^{23,24}$ During surgery and CSD recordings, the animals breathed spontaneously, and their body temperature was maintained at $37^{\circ} \mathrm{C} \pm 0.5^{\circ} \mathrm{C}$ by the use of a self-regulating heating pad (TMP 5-b; Supertech Instruments, Budapest, Hungary) and a rectal probe. A trachea cannula was inserted, and heads of the animals were fixed in a stereotaxic frame. After exposure of the skull, three holes ( $2 \mathrm{~mm}$ in diameter) were drilled on the left side under cooling with saline with $3 \mathrm{~mm}$ between each hole (see Figure 1). Two holes were used for electrophysiological recordings above the sensorimotor cortex (bregma [Br] 1, 2 for $\mathrm{E}_{1},-2,2$ for $\mathrm{E}_{2}$, indicating distances in millimeters in the anterior-posterior and the medial-lateral axes from the 


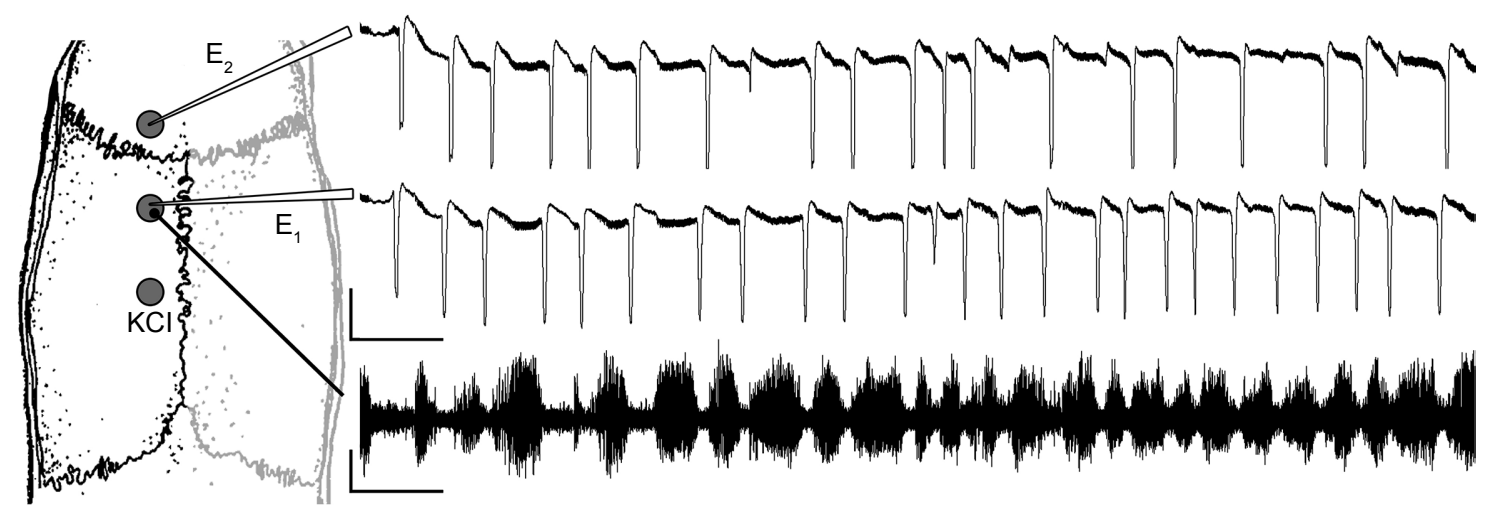

Figure I Experimental design and representative recording from the 2-hour period following $\mathrm{KCl}$ administration.

Notes: On the left, filled circles indicate the exposed skull areas ( $1,-2$, and $-5 \mathrm{~mm}$ from the bregma in the anterior-posterior axis, respectively; $2 \mathrm{~mm}$ from the bregma in the medial-lateral axis). $\mathrm{KCl}(\mathrm{I} \mathrm{M})$ was applied at the posterior hole. Direct-current electrodes $\mathrm{E}_{1}$ and $\mathrm{E}_{2}$ were positioned at a distance of 3 mm from each other. The silver electrocorticography electrode was placed next to the $E_{1}$ electrode. Vertical bars $10 \mathrm{mV}$ (direct current) and $500 \mu \mathrm{V}$. Horizontal bar 10 minutes.

$\mathrm{Br}$, respectively). In the third hole $(\mathrm{Br}-5,2)$, the dura and arachnoid mater were carefully removed, allowing access for the chemical induction of CSD. Before the recordings, the cortex was allowed to recover for 30 minutes.

\section{Electrophysiological recordings}

Both the slow direct current (DC)-potential change and spontaneous cortical electrical activity accompanying CSD were continuously recorded for 4 hours. For the DC recordings, glass microelectrodes (1.5-2 M 2 ) filled with artificial cerebrospinal fluid connected to an $\mathrm{Ag} / \mathrm{AgCl}$ wire were inserted into the cortex to a depth of $800 \pm 100 \mu \mathrm{m}$, corresponding to cortical layer V. Electrocorticography (ECoG) was recorded from the surface of the dura with the aid of a silver electrode next to the posterior DC electrode $(\mathrm{Br}-2,2)$. ECoG was recorded to monitor the depth of anesthesia and to verify the CSDs that cause a notable reduction in the ECoG amplitudes (Figure 1). In both types of recordings, common reference electrodes of the same type were placed in the masticatory muscle. DC-potential changes and ECoG were recorded by connecting the electrodes to EXP-E amplifiers (Experimetria Ltd, Budapest, Hungary).

Following offline data processing with laboratorydeveloped software, we examined the frequency, amplitude, time to half amplitude, velocity of propagation, and propagation failure of the CSD waves. Furthermore, we compared these parameters separately between the two recording DC electrodes $\left(\mathrm{E}_{1}, \mathrm{E}_{2}\right)$ and between the first and second hour of recording following $\mathrm{KCl}$ application. The velocity of CSDwave propagation was calculated from the time required for a CSD wave to travel the distance between the two cortical recording points. This time was measured by using the beginning of the first descending phase of the slow DCpotential change as the initial point, as previously described by Batista-de-Oliveira et al. ${ }^{25} \mathrm{DC}$ shifts not exceeding the threshold of $5 \mathrm{mV}$ were excluded from data analysis.

\section{Experimental groups and treatments}

The applied pharmacons and the saline (used as control and vehicle) were injected intraperitoneally prior to $\mathrm{KCl}$ administration at the given time point (Figure 2). The control group $(\mathrm{n}=6)$ received $2.5 \mathrm{~mL}$ of saline, whereas the NTG group $(\mathrm{n}=5)$ was treated with $10 \mathrm{mg} / \mathrm{kg}$ NTG (Nitro Pohl; G PohlBoskamp GmbH and Co KG, Hohenlockstedt, Germany) at minute 10. In the NTG + sumatriptan group $(n=5)$, sumatriptan (Imigran; GlaxoSmithKline PLC, London, UK) at a dose of $0.6 \mathrm{mg} / \mathrm{kg}$ was applied 10 minutes after the NTG injection, in accordance with Bates et al. ${ }^{26}$ The KYNA analogues (SZR-105 and SZR-109; each n=5) were both administered at a dose of $0.5 \mathrm{mmol} / \mathrm{kg}$ at minute 90 (80 minutes after NTG administration, 30 minutes before CSD induction).

The KYNA analogues SZR-105 and SZR-109 are novel neuroactive KYNA derivatives, substituted at C3. According

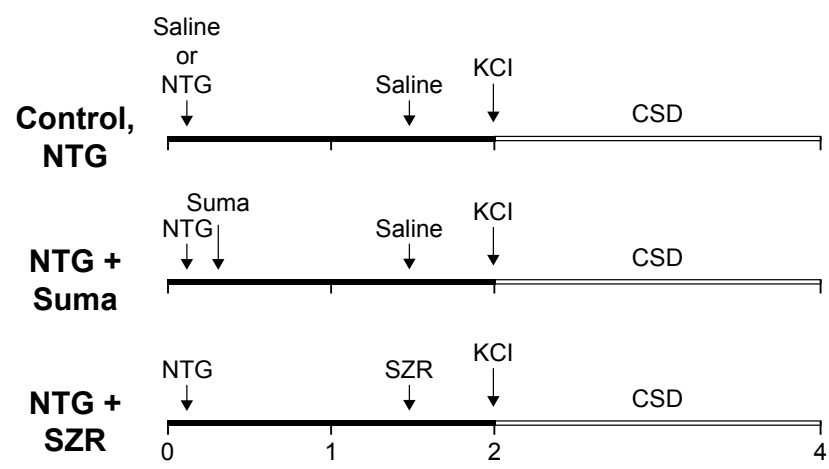

Figure 2 Experimental design of the different groups. Numbers represent hours of recording.

Abbreviations: NTG, nitroglycerin; CSD, cortical spreading depression; Suma, sumatriptan. 
to preliminary studies, these molecules might be effective neuroprotective or effective compounds in certain neurological diseases (eg, in Alzheimer's disease, Parkinson's disease, Huntington's disease, amyotrophic lateral sclerosis, stroke, multiple sclerosis, and migraine).

In all groups, CSD waves were continuously elicited for 2 hours from the 120th min by placing a cotton ball (diameter $1 \mathrm{~mm}$ ) soaked with $1 \mathrm{M} \mathrm{KCl}$ solution onto the cortex through the posterior hole. To keep the cotton ball moist, it was impregnated with $5 \mu \mathrm{L}$ of $\mathrm{KCl}$ solution every 15 minutes.

\section{Statistical analysis}

IBM SPSS 20 software was used for the analyses. Electrophysiological data between the two electrodes were compared separately by the use of nonparametric related-sample Friedman two-way analysis of variance (ANOVA) by rank. To analyze the differences between the groups, nonparametric independent-sample Kruskal-Wallis ANOVA was used. Data are expressed as mean and standard deviation. Differences were considered statistically significant when $P \leq 0.05$.

\section{Results}

The slow potential change in the DC-potential recordings clearly denoted the presence of CSDs after $\mathrm{KCl}$ stimulation, which could also be easily detected by the farther, second DC electrode $\left(\mathrm{E}_{2}\right)$. In some cases, more CSDs were detected by $\mathrm{E}_{2}$, which can be attributed to a very slight depolarization of the area under $\mathrm{E}_{1}$.

After analysis of the data, the amplitude, velocity, and time to half amplitude of the CSDs showed no significant differences between the groups (Table 1). None of these parameters differed significantly when comparing the data obtained from the two electrodes separately (Table 1) or when comparing the first and the second hour (data not shown). However, a slight increase in the amplitudes was observed at $\mathrm{E}_{2}$.

In the control group, we observed a constantly occurring propagation failure $(20 \% \pm 1 \%)$ (Figure $3 \mathrm{~A})$, which resulted in decreased CSD numbers recorded by $\mathrm{E}_{2}$. This tendency was observed in almost all the recordings (Figure 3A), and proved to be significant $(P=0.046)$ based on pairwise comparison (two-way Friedman's ANOVA). The CSD numbers (similarly to all other groups) recorded by either $\mathrm{E}_{1}$ or $\mathrm{E}_{2}$ showed no difference between the first and second hours of $\mathrm{KCl}$ administration $\left(\mathrm{E}_{1} 9.3 \pm 4,10.5 \pm 4 ; \mathrm{E}_{2} 8.0 \pm 3\right.$, 7.4 \pm 2 ) (Figure 3B).

The administration of NTG slightly but insignificantly elevated CSD numbers and significantly changed the ratio of propagation (1.02 \pm 0.1$)$. In this case, no significant difference was observed between the electrodes, as opposed to the control group (Figure 3A). In the NTG + sumatriptan group, CSD numbers decreased when sumatriptan was applied 10 minutes after NTG treatment. Significant differences were detectable in multiple comparisons of CSD numbers recorded by $\mathrm{E}_{2}$ in the different groups (Figure 3B). In this group, the ratio of propagation $(1.03 \pm 0.1)$ was similar to that in the NTG group (Figure 3A and $\mathrm{C}$ ).

Both of the KYNA analogues applied after NTG injection restored $\mathrm{CSD}$ numbers and the ratio of propagation to the control level (Figure 3 ). In each animal ( $n=5$ in both KYNA analogue-treated groups), the number of CSDs at $\mathrm{E}_{2}$ was less than or at most equal with that observed at $E_{1}$, which resulted in significant decreases in related-sample analyses ( $P=0.046$ and $P=0.025$ for the two KYNA-analogue groups, respectively; Figure $3 \mathrm{~A}$ and $\mathrm{C}$ ).

\section{Discussion}

Despite the large amount of accumulated knowledge about the processes involved in migraine pathogenesis, the available treatments are at present often limited and suboptimal. Therefore, new experimental models, candidate compounds and drug targets are still the focus of antimigraine research. ${ }^{27,28}$ Cortical excitability in CSD is a physiological correlate of aura in migraine, ${ }^{29,30}$ which prompted us to investigate the hypothesis whether NTG can influence the characteristics of CSDs.

Table I Parameters of CSD

\begin{tabular}{|c|c|c|c|c|c|c|c|c|}
\hline & \multirow[t]{2}{*}{$\mathbf{n}$} & \multirow[t]{2}{*}{$\begin{array}{l}\text { Propagation } \\
\text { velocity }(\mathrm{mm} / \mathrm{min})\end{array}$} & \multicolumn{2}{|c|}{ Amplitude (mV) } & \multicolumn{2}{|c|}{$\begin{array}{l}\text { Time to half } \\
\text { amplitude (seconds) }\end{array}$} & \multicolumn{2}{|c|}{$\begin{array}{l}\text { Number of CSDs/ } \\
2 \text { hours }\end{array}$} \\
\hline & & & $\mathbf{E}_{1}$ & $\mathbf{E}_{2}$ & $\mathbf{E}_{1}$ & $\mathbf{E}_{2}$ & $\mathbf{E}_{1}$ & $\mathbf{E}_{2}$ \\
\hline Control & 6 & $2.93 \pm 0.5$ & $25.4 I \pm 4.7$ & $29.04 \pm 4.6$ & $26.5 \pm 12.2$ & $27.39 \pm 8$ & $19.83 \pm 6.9$ & $15.33 \pm 4.1$ \\
\hline NTG & 5 & $2.97 \pm 0.5$ & $24.96 \pm 5$ & $26.24 \pm 6.1$ & $24.21 \pm 9.1$ & $25.07 \pm 8.9$ & $22.6 \pm 7.1$ & $22.80 \pm 5.7$ \\
\hline NTG + Suma & 5 & $2.84 \pm 0.3$ & $25.87 \pm 5.9$ & $28.29 \pm 6.9$ & $28.03 \pm 6.1$ & $25.54 \pm 6.7$ & $13.2 \pm 4.1$ & $13.8 \pm 5.9 *$ \\
\hline NTG + SZR- 105 & 5 & $2.93 \pm 0.7$ & $26 \pm 5.6$ & $28.53 \pm 5.1$ & $28.5 \pm 7.2$ & $31.94 \pm 8.5$ & $22 \pm 3.9$ & $16.8 \pm 2.4$ \\
\hline NTG + SZR-109 & 5 & $2.78 \pm 0.4$ & $26.47 \pm 5.2$ & $27.95 \pm 5.4$ & $29.8 \pm 8.6$ & $29.61 \pm 7.4$ & $20.6 \pm 3.2$ & $15.6 \pm 2.1$ \\
\hline
\end{tabular}

Notes: $* P=0.032$ (multiple comparison of NTG groups by Kruskal-Wallis ANOVA); values are mean \pm SD.

Abbreviations: CSD, cortical spreading depression; NTG, nitroglycerin; Suma, sumatriptan; ANOVA, analysis of variance; SD, standard deviation. 

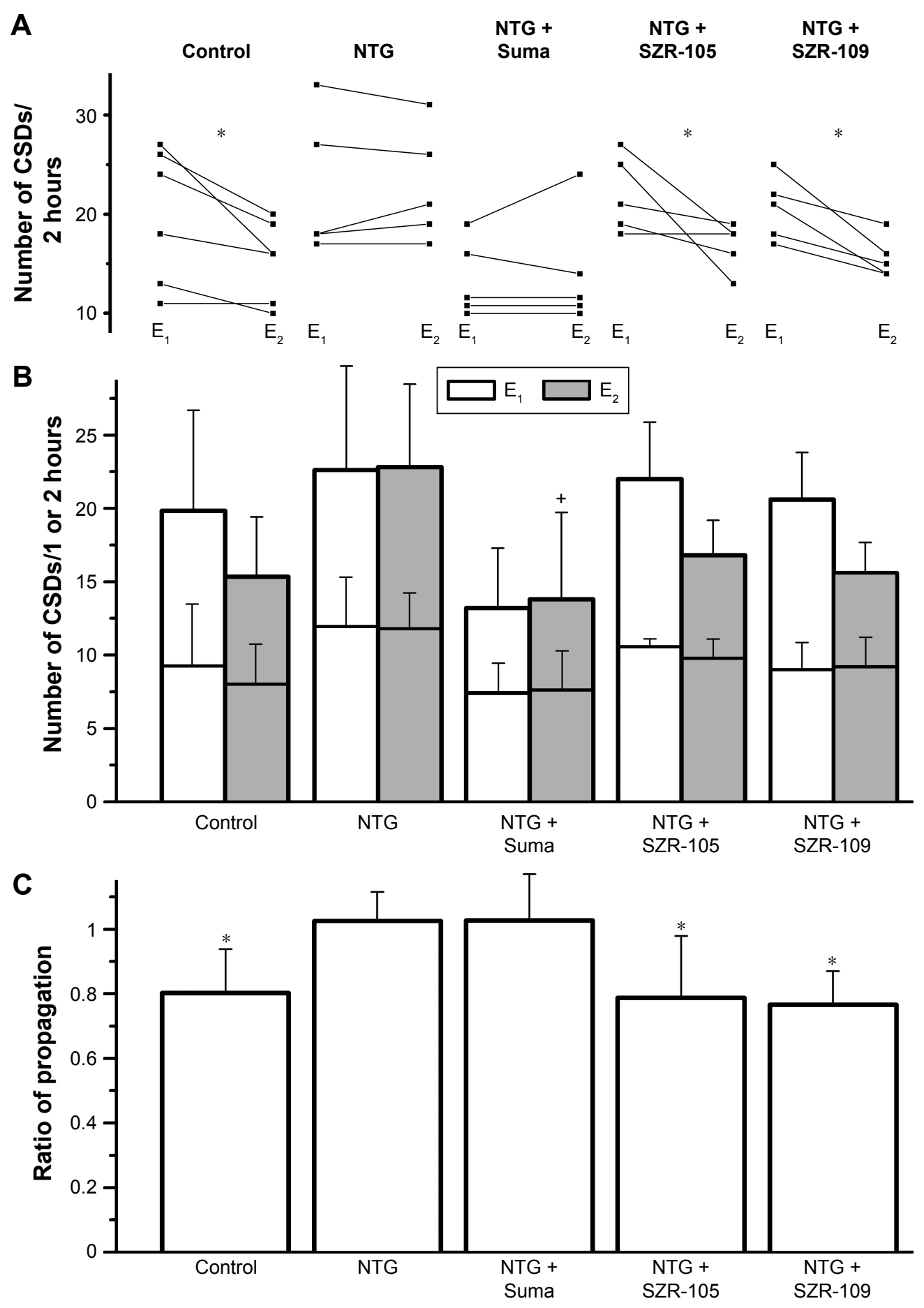

Figure 3 CSD frequency and ratio of propagation.

Notes: (A) Number of CSDs/2 hours in all experiments and groups. The connecting lines show the data from single experiments, recorded by $E_{1}$ and $E_{2}$. The slope of the lines indicates the ratio of propagation, based on the different CSD number recorded by the two electrodes. In this parameter, significant differences were observed in the control group and both of the NTG + SZR groups (pairwise comparison within the groups with Friedman's ANOVA; $* P=0.046,0.046,0.025)$. (B) Average $( \pm S D)$ CSD numbers in the different groups, detected by $E_{1}$ and $E_{2}$. Significant decrease in CSD number recorded by $E_{2}$ was observed in the NTG + Suma group using multiple comparison between the groups and electrodes (Kruskal-Wallis ANOVA; ${ }^{+} P=0.032$ ). Horizontal lines within bars represents CSD number (mean $\left.\pm S D\right)$ in the first hour. There was no significant difference between the first and second hour recorded by either of the electrodes in any groups. (C) Average $( \pm S D)$ ratio of propagation in the different groups (CSDs at $E_{2} / C S D s$ at $\left.E_{1}\right)$. Abbreviations: CSD, cortical spreading depression; NTG, nitroglycerin; ANOVA, analysis of variance; SD, standard deviation; Suma, sumatriptan.

Based on a number of studies, CSD is an "all or none" phenomenon, making it difficult to detect remarkable changes in various CSD parameters following the acute administration of potential antimigraine drugs. ${ }^{31-33}$ The most relevant CSD parameters include the susceptibility (examined by increasing electrical stimulation), the frequency (in cases of continuous $\mathrm{KCl}$ application), and the velocity of SD. Of note, the amplitude and the duration are quite constant in most experiments. ${ }^{34}$ 
In the present study, the progression of the depolarization wave failed between the two recording points in $20 \%$ of the CSDs, indicative of the presence of inhibitory effects in the cortical tissue under physiological conditions (notably during anesthesia). However, the propagation of the CSDs was unimpeded after the systemic administration of NTG, molecules of which may provide support against homeostatic and energetic disturbances caused by the CSDs, ${ }^{35}$ resulting in enhanced propagation. In contrast to our results, some studies have proved an inverse relationship between tissue NO level and susceptibility in human and rodent cortices ${ }^{36}$ and also in chicken retina. ${ }^{37}$ Low NO level or inhibited NOS increased tissue susceptibility to CSD. Furthermore, CSDs themselves increase NO levels, ${ }^{38}$ and thus additional NTG may contribute to the release or appearance of other NO metabolites. Further investigations are needed to identify the detailed mechanisms and to explore the active substances that take part in this phenomenon. Nevertheless, in point of fact, we suggest that the altered physiological state caused by NTG administration can be influenced more easily than the baseline parameters of CSDs; therefore, this model may provide an opportunity to test compounds with only moderate or subtle effects via the assessment of the ratio of propagation. Our results clearly demonstrate the effect of NTG administration on CSD propagation. There have been limited studies to investigate the NTG effect on CSD. Read et al confirmed that NTG causes elevated brain NO levels in anesthetized cats. ${ }^{39}$ The susceptibility, duration, and amplitude of CSDs were not changed by NTG; however, CSD-induced local NO concentration was elevated. In another study, Bates et al performed experiments on mice to investigate CSD susceptibility following NTG administration, but they did not find any differences between the groups. ${ }^{26}$ In our study, sumatriptan decreased the frequency of CSDs; however, the ratio of propagation remained similar to that seen in the NTG group. Sumatriptan has been proven to be effective in migraine by acting on the serotonin system through the activation of $5-\mathrm{HT}_{1 \mathrm{~B} / 1 \mathrm{D}}$ receptors. Decreased 5-HT level is closely associated with headache. ${ }^{40}$ It is known that 5 -HT receptors are involved in neurogenic cranial vascular changes. Indeed, meningeal blood flow increases following the application of the $5-\mathrm{HT}_{7}$-receptor agonist, whereas $5-\mathrm{HT}_{7}$-receptor antagonist plus sumatriptan as a $5-\mathrm{HT}_{1 \mathrm{~B} / 1 \mathrm{D}}$ agonist causes decreased blood flow. ${ }^{41}$ In a prior study, sumatriptan decreased the concentration of NO following CSD induction, ${ }^{42}$ and alleviated mechanical and thermal allodynia that developed as a result of NTG administration. ${ }^{26}$ In a vessel-free preparation of chicken retina, sumatriptan blocked the SD in a concentration-dependent manner, which indicates that the effect must be related to neuronal tissue. ${ }^{43}$ Nevertheless, there is no evidence that sumatriptan can strongly modulate CSDs. ${ }^{44,45}$ In the present study, we cannot give a full explanation of the mechanisms underlying our results. However, we suggest that the 5-HT receptors directly involved in CSD could contribute to this effect.

This is the first study with these novel KYNA analogues demonstrating an effect; indeed, the elevated ratio of propagation was restored to the control level by these compounds, whereas the number of CSDs remained largely unchanged. There are several possibilities to explain these results, including the potential modulatory effect of these analogues on glutamatergic transmission by means of the inhibition of NMDA receptors, similarly to KYNA; however, further investigations are needed to be conclusive at this point. The beneficial effects of KYNA ${ }^{46}$ and its different analogues have been proven in different migraine models. The KYNA analogue SZR-72 mitigated systemic NTG-induced increase in the number of neurons expressing c-Fos ${ }^{47}$ and nNOS. ${ }^{48}$ Furthermore, SZR-72 attenuated the NTG-induced decrease of histochemical changes in the caudal trigeminal nucleus. ${ }^{49}$ The dissimilar effects of sumatriptan and KYNA analogues on CSDs suggest two inhibitory mechanisms. Further investigations are required to clarify the mechanisms underlying these effects; however, we can conclude that sumatriptan acts on the generation of the waves, whereas KYNA analogues interfere with the propagation of CSDs. Nevertheless, we cannot exclude the possibility that the analogues may counteract the effect of NTG and thereby restore normal conditions.

\section{Conclusion}

In summary, peripheral administration of NTG enhanced the propagation of CSDs. Sumatriptan, a widely used antimigraine drug, caused detectable changes in CSD frequency, which indicates the relevance of our model. Additionally, the elevated ratio of CSD propagation caused by NTG was decreased by SZR-105 and SZR-109. These results clearly show the effectiveness of these promising KYNA analogues. Here, we have presented a combined experimental migraine model for testing drugs and other pharmacological agents affecting processes involved in the pathomechanism of migraine.

\section{Acknowledgments}

This work was supported by projects OTKA KI05077 and TÁMOP-4.2.2.A-11/1/KONV-2012-0052, the European Union and the state of Hungary, cofinanced by the European Social Fund in the framework of TÁMOP 
4.2.4.A/2-11-1-2012-0001 National Excellence Program, by the MTA-SZTE Neuroscience Research Group, by the Hungarian Brain Research Program (grant KTIA_13_NAPA-III/9), by GINOP-2.3.2-15-2016-00034 and by the EUROHEADPAIN (FP7-Health 2013 Innovation, grant 602633). The authors gratefully thank Dr Levente Szalárdy for linguistic correction of the manuscript.

\section{Disclosure}

The authors report no conflicts of interest in this work.

\section{References}

1. Lipton RB, Bigal ME. Toward an epidemiology of refractory migraine: current knowledge and issues for future research. Headache. 2008; 48(6):791-798.

2. Jansen-Olesen I, Tfelt-Hansen P, Olesen J. Animal migraine models for drug development: status and future perspectives. CNS Drugs. 2013; 27(12):1049-1068.

3. Ayata C. Cortical spreading depression triggers migraine attack: pro. Headache. 2010;50(4):725-730.

4. Somjen GG. Aristides Leão's discovery of cortical spreading depression. J Neurophysiol. 2005;94(1):2-4.

5. Tottene A, Urbani A, Pietrobon D. Role of different voltage-gated $\mathrm{Ca} 2+$ channels in cortical spreading depression: specific requirement of P/Q-type Ca2+ channels. Channels (Austin). 2011;5(2):110-114.

6. Peeters M, Gunthorpe MJ, Strijbos PJ, Goldsmith P, Upton N, James MF. Effects of pan- and subtype-selective N-methyl-D-aspartate receptor antagonists on cortical spreading depression in the rat: therapeutic potential for migraine. J Pharmacol Exp Ther. 2007;321(2):564-572.

7. Richter F, Ebersberger A, Schaible HG. Blockade of voltage-gated calcium channels in rat inhibits repetitive cortical spreading depression. Neurosci Lett. 2002;334(2):123-126.

8. Ayata C. Spreading depression: from serendipity to targeted therapy in migraine prophylaxis. Cephalalgia. 2009;29(10):1095-1114.

9. Haghir H, Kovac S, Speckmann EJ, Zilles K, Gorji A. Patterns of neurotransmitter receptor distributions following cortical spreading depression. Neuroscience. 2009;163(4):1340-1352.

10. Colonna DM, Meng W, Deal DD, Busija DW. Nitric oxide promotes arteriolar dilation during cortical spreading depression in rabbits. Stroke. 1994;25(12):2463-2470.

11. Piper RD, Lambert GA, Duckworth JW. Cortical blood flow changes during spreading depression in cats. Am J Physiol. 1991;261(1 Pt 2): H96-H102.

12. Olesen J, Thomsen LL, Iversen H. Nitric oxide is a key molecule in migraine and other vascular headaches. Trends Pharmacol Sci. 1994; 15(5):149-153.

13. Tassorelli C, Joseph SA. Systemic nitroglycerin induces Fos immunoreactivity in brainstem and forebrain structures of the rat. Brain Res. 1995;682(1-2):167-181.

14. Greco R, Meazza C, Mangione AS, et al. Temporal profile of vascular changes induced by systemic nitroglycerin in the meningeal and cortical districts. Cephalalgia. 2011;31(2):190-198.

15. Strecker T, Dux M, Messlinger K. Nitric oxide releases calcitonin-generelated peptide from rat dura mater encephali promoting increases in meningeal blood flow. J Vasc Res. 2002;39(6):489-496.

16. Tassorelli C, Joseph SA. NADPH-diaphorase activity and Fos expression in brain nuclei following nitroglycerin administration. Brain Res. 1995;695(1):37-44.

17. Schwarcz R, Bruno JP, Muchowski PJ, Wu HQ. Kynurenines in the mammalian brain: when physiology meets pathology. Nat Rev Neurosci. 2012;13(7):465-477.

18. Vecsei L, Szalardy L, Fulop F, Toldi J. Kynurenines in the CNS: recent advances and new questions. Nat Rev Drug Discov. 2013;12(1):64-82.
19. Knyihár-Csillik E, Chadaide Z, Okuno E, et al. Kynurenine aminotransferase in the supratentorial dura mater of the rat: effect of stimulation of the trigeminal ganglion. Exp Neurol. 2004;186(2):242-247.

20. Knyihár-Csillik E, Toldi J, Krisztin-Péva B, et al. Prevention of electrical stimulation-induced increase of c-Fos immunoreaction in the caudal trigeminal nucleus by kynurenine combined with probenecid. Neurosci Lett. 2007;418(2):122-126.

21. Knyihár-Csillik E, Toldi J, Mihály A, et al. Kynurenine in combination with probenecid mitigates the stimulation-induced increase of c-Fos immunoreactivity of the rat caudal trigeminal nucleus in an experimental migraine model. J Neural Transm (Vienna). 2007;114(4):417-421.

22. Salvati P, Ukmar G, Dho L, et al. Brain concentrations of kynurenic acid after a systemic neuroprotective dose in the gerbil model of global ischemia. Prog Neuropsychopharmacol Biol Psychiatry. 1999;23(4): 741-752.

23. Gorelova NA, Krivánek J, Bures J. Functional and metabolic correlates of long series of cortical spreading depression waves in rats. Brain Res. 1987;404(1-2):379-381

24. Kudo C, Nozari A, Moskowitz MA, Ayata C. The impact of anesthetics and hyperoxia on cortical spreading depression. Exp Neurol. 2008; 212(1):201-206.

25. Batista-de-Oliveira M, Lopes AA, Mendes-da-Silva RF, Guedes RC. Aging-dependent brain electrophysiological effects in rats after distinct lactation conditions, and treadmill exercise: a spreading depression analysis. Exp Gerontol. 2012;47(6):452-457.

26. Bates EA, Nikai T, Brennan KC, et al. Sumatriptan alleviates nitroglycerin-induced mechanical and thermal allodynia in mice. Cephalalgia. 2010;30(2):170-178.

27. Gupta S, Villalón CM. The relevance of preclinical research models for the development of antimigraine drugs: focus on 5-HT(1B/1D) and CGRP receptors. Pharmacol Ther. 2010;128(1):170-190.

28. Link AS, Kuris A, Edvinsson L. Treatment of migraine attacks based on the interaction with the trigemino-cerebrovascular system. J Headache Pain. 2008;9(1):5-12.

29. Bowyer SM, Aurora KS, Moran JE, Tepley N, Welch KM. Magnetoencephalographic fields from patients with spontaneous and induced migraine aura. Ann Neurol. 2001;50(5):582-587.

30. Hadjikhani N, Del Rio MS, Wu O, et al. Mechanisms of migraine aura revealed by functional MRI in human visual cortex. Proc Natl Acad Sci U S A. 2001;98(8):4687-4692.

31. Ayata C, Jin H, Kudo C, Dalkara T, Moskowitz MA. Suppression of cortical spreading depression in migraine prophylaxis. Ann Neurol. 2006; 59(4):652-661.

32. Costa C, Tozzi A, Rainero I, et al. Cortical spreading depression as a target for anti-migraine agents. J Headache Pain. 2013;14:62.

33. Eikermann-Haerter K, Lee JH, Yalcin N, et al. Migraine prophylaxis, ischemic depolarizations, and stroke outcomes in mice. Stroke. 2015; 46(1):229-236.

34. Eikermann-Haerter K, Can A, Ayata C. Pharmacological targeting of spreading depression in migraine. Expert Rev Neurother. 2012;12(3): 297-306.

35. Wang M, Obrenovitch TP, Urenjak J. Effects of the nitric oxide donor, DEA/NO on cortical spreading depression. Neuropharmacology. 2003; 44(7):949-957.

36. Petzold GC, Haack S, von Bohlen und Halbach O, et al. Nitric oxide modulates spreading depolarization threshold in the human and rodent cortex. Stroke. 2008;39(4):1292-1299.

37. Ulmer HJ, de Lima VM, Hanke W. Effects of nitric oxide on the retinal spreading depression. Brain Res. 1995;691(1-2):239-242.

38. Read SJ, Smith MI, Hunter AJ, Upton N, Parsons AA. SB-220453, a potential novel antimigraine agent, inhibits nitric oxide release following induction of cortical spreading depression in the anaesthetized cat. Cephalalgia. 2000;20(2):92-99.

39. Read SJ, Smith MI, Hunter AJ, Parsons AA. Enhanced nitric oxide release during cortical spreading depression following infusion of glyceryl trinitrate in the anaesthetized cat. Cephalalgia. 1997;17(3): 159-165. 
40. Lambert GA, Hoskin KL, Zagami AS. Cortico-NRM influences on trigeminal neuronal sensation. Cephalalgia. 2008;28(6):640-652.

41. Wang X, Fang Y, Liang J, Yan M, Hu R, Pan X. 5-HT7 receptors are involved in neurogenic dural vasodilatation in an experimental model of migraine. J Mol Neurosci. 2014;54(2):164-170.

42. Read SJ, Parsons AA. Sumatriptan modifies cortical free radical release during cortical spreading depression: a novel antimigraine action for sumatriptan? Brain Res. 2000;870(1-2):44-53.

43. Maranhão-Filho PA, Martins-Ferreira $\mathrm{H}$, Vincent MB, Ribeiro LJ, Novis SA. Sumatriptan blocks spreading depression in isolated chick retina. Cephalalgia. 1997;17(8):822-825.

44. Ingvardsen BK, Laursen H, Olsen UB, Hansen AJ. Possible mechanism of c-Fos expression in trigeminal nucleus caudalis following cortical spreading depression. Pain. 1997;72(3):407-415.

45. Bradley DP, Smith MI, Netsiri C, et al. Diffusion-weighted MRI used to detect in vivo modulation of cortical spreading depression: comparison of sumatriptan and tonabersat. Exp Neurol. 2001;172(2):342-353.
46. Oláh G, Herédi J, Menyhárt A, et al. Unexpected effects of peripherally administered kynurenic acid on cortical spreading depression and related blood-brain barrier permeability. Drug Des Devel Ther. 2013; 16(7):981-987.

47. Knyihar-Csillik E, Mihaly A, Krisztin-Peva B, et al. The kynurenate analog SZR-72 prevents the nitroglycerol-induced increase of c-Fos immunoreactivity in the rat caudal trigeminal nucleus: comparative studies of the effects of SZR-72 and kynurenic acid. Neurosci Res. 2008; 61(4):429-432.

48. Vámos E, Párdutz A, Varga $\mathrm{H}$, et al. L-Kynurenine combined with probenecid and the novel synthetic kynurenic acid derivative attenuate nitroglycerin-induced nNOS in the rat caudal trigeminal nucleus. Neuropharmacology. 2009;57(4):425-429.

49. Vámos E, Fejes A, Koch J, et al. Kynurenate derivative attenuates the nitroglycerin-induced CamKII $\alpha$ and CGRP expression changes. Headache. 2010;50(5):834-843.

\section{Publish your work in this journal}

Drug Design, Development and Therapy is an international, peerreviewed open-access journal that spans the spectrum of drug design and development through to clinical applications. Clinical outcomes, patient safety, and programs for the development and effective, safe, and sustained use of medicines are the features of the journal, which has also been accepted for indexing on PubMed Central. The manuscript management system is completely online and includes a very quick and fair peer-review system, which is all easy to use. Visit http://www.dovepress.com/testimonials.php to read real quotes from published authors.

Submit your manuscript here: http://www.dovepress.com/drug-design-development-and-therapy-journal 